\title{
Identifying Critical Success Factors for ERP in SMEs through a Case Study
}

\author{
Veena Bansal
}

\begin{abstract}
ERP systems have been around since 1990s. Many organisations across the world have deployed ERP systems since then. An ERP system is a very complex system and its deployment involves the entire organisation. But not all ERP projects that are started end successfully. In this article, we analyse a failed ERP project in a small organisation in the capital region of India. We use critical success factors (CFSs) that have been identified in literature for analysis. The CSFs that contributed to the failure turned out to be- poor project management, lack of management support, ineffective external consultant, ineffective vendor's team and wrong package selection.
\end{abstract}

Index Terms-Business integration, CSF, ERP, SMEs

\section{INTRODUCTION}

In today's dynamic and turbulent business environment, there is a strong need for organisations to become globally competitive. The survival guide to competitiveness is to be closer to the customer and deliver value-added product and services in the shortest possible time. This, in turn, demands integration of the business processes of an enterprise, which is the stronghold of ERP. Enterprise Resource Planning (ERP), is a software driven business management system that integrates all facets of the business. Organisations of all sizes, small, medium and large are making an effort to integrate their businesses by deploying ERP systems. We will focus on small and medium enterprises (SMEs). Studying SMEs is important because in many countries SMEs are major contributors to the economy. Many countries have a separate ministry for SMEs. We have a ministry for Micro, Small and Medium Enterprises that has reported 13 million to be the number of SMEs in India. However, there is no universal definition of SMEs and different countries have different definitions of SMEs (refer to Table i). There are close to 200 ERP vendors, majority of which work with SMEs. ERP deployments are not always successful [1]. Researchers have studied ERP projects and have identified factors that contribute to the success of an ERP project referred to as critical success factors (CSF) [2]. The objective is to study an ERP project of a small company in the national capital region of India. Let us call this company RetailS. Their ERP project completely failed and it had to be abandoned. RetailS started the project in Oct 2009 and finally abandoned it in early 2010 . The company followed all the steps but the project didn't succeed.

In order to study and analyse the project, we had an

Manuscript received January 20, 2013; revised March 18, 2013.

Veena Bansal is with Department of Industrial and Management Engineering, Indian Institute of Technology Kanpur, Kanpur-208016, India (e-mail: veena@iitk.ac.in) extensive interaction with the CMD, one of the managing director, the consultant, the implementation partner and his team. Notes were taken during interactions. There were very few documents to be examined as most of the processes were described to us. The documents that were examined consisted of Sales Order, Purchase Order, Price List etc. We also looked at their records that mainly consisted of spreadsheets. We first did a literature review of the CSFs. We have listed critical success factors that have been identified in literature for SMEs for various developing countries in Section II.

We provide details of the company in Section III and its reasons for wanting an ERP system. We describe the implementation effort and its outcome that turned out to be a failure in Section IV. We then evaluate the reasons for the failure with the known causes from literature in Section V. Section VI concludes the paper.

TABLE I: DEFINITION OF SMES IN SOME COUNTRIES (MANU. STANDS FOR

\begin{tabular}{|c|c|c|}
\multicolumn{2}{c|}{ MANUFACTURING). } \\
Type & Country & $\begin{array}{c}\text { Investment } \\
\text { between(USD) }\end{array}$ \\
\hline Manu. & India & 50,000 and $2 \mathrm{M}$ \\
\hline Manu. & Malayasia & 80,000 and $7 \mathrm{M}$ \\
\hline Manu. & Iran & $20 \mathrm{M}$ and $200 \mathrm{M}$ \\
\hline Service & India & 20,000 and $1 \mathrm{M}$ \\
\hline Manu. & China & $6.3 \mathrm{M}$ and $63 \mathrm{M}$ \\
\hline Manu. & Singapore & $6.3 \mathrm{M}$ and $12 \mathrm{M}$ \\
\hline Service & Iran & $1 \mathrm{M}$ and $20 \mathrm{M}$ \\
\hline
\end{tabular}

\section{CRITICAL SUCCESS FACTORS}

Many ERP projects fail and there are close to 40 reasons listed in the literature for failure of an ERP project [3] for SMEs. Various critical success factors (CSFs) have been identified in the literature. The maximum number of CSFs identified for SMEs are 94 that have been put in 15 categories [4] that we will use. We enumerate critical success factors (CSF) that have been identified for SMEs by researchers for different developing countries in Table II. The CSFs have also been ranked but we have not included the ranks in the tables. We don't consider ranks to be important because it has been shown that CSFs are not independent [5]. For instance, Top management support has an impact on project communication that has an impact on cooperation at different levels. Effective education and training influence cooperation from the end users. If the management is supportive, the project communication improves. On the other hand, if the management is not supportive, the project communication deteriorates that impacts cooperation in a negative way. Refer to [6]-[10] for CSF for Indian SMEs, [11]-[12] for China, [13]-[15] for Malaysia, [16] for Egypt and [17] for Iran. 
Equipped with CSFs, let us now learn about Retails and its reasons of implementing ERP system in the organisation.

TABLE II: CRITICAL SUCCESS FACTORS FOR SMES FOR DIFFERENT COUNTRIES AND REFERENCES (MGMT. STANDS FOR MANAGEMENT, COMM. FOR COMMUNICATION, ORG. FOR ORGANISATION)

\begin{tabular}{|l|l|}
\hline Project Mgmt. & $\begin{array}{l}\text { Support of Top } \\
\text { Mgmt }\end{array}$ \\
\hline Vendor Support & Implementation Strategy \\
\hline Education and Training & Package Selection \\
\hline Organizational Characteristics & Data management \\
\hline Change Management & Competence of Project Team \\
\hline ERP system & User Involvement \\
\hline Project Monitoring & Environment \\
\hline Software Development & \\
\hline & \\
\hline
\end{tabular}

\section{DeTAILS OF THE COMPANY AND REASONS FOR} IMPLEMENTING ERP

Retails was formed in 1995. The company primarily retails metallic packaging material. It also deals in some food products. The turnover of company is about 10 million USD and the company has less than 30 employees. Retails has a CMD, 2 managing directors, a sales department, a purchase department and a finance $\&$ accounting department.

The management consists of the CMD and the two managing directors. All three of them can make day-to-day decisions but the policy decisions cannot be taken without the consent of the CMD. Purchase and sales department have approximately 10 persons each. Finance department consists of 2 full time employees and one part time consultant who visits as and when required. The turnover of the company is 30,000 USD per person per month. This figure indicates the efficiency of the company. None of the material that RetailS deals in is manufactured by the company. The products that Retais deals in are very complex and the parameters associated with a product are just too many.

A salesman takes orders from a customer and then gets the material from a supplier directly shipped to the buyer. This seemingly simple process involves many steps and multiple outcomes for each step. The simplified process is shown in Figure 1. The sales man takes orders from a customer and then gets the material from a supplier directly shipped to the buyer. Let us look at this process stepwise.

1) The salesman of Retails may approach a potential buyer and ask him his requirements. There are four possibilities:

- The effort to contact may fail due to change in contact details.

- The potential buyer may not have any requirements.

- The potential buyer may ask the sales man to contact later.

- If there is a requirement, he may give him his approximate requirements in terms of products, price, quantity and timeline.

In case of $1 \mathrm{a}$, the salesman would record his effort in his log book and make another attempt to get the changed contact information. In case of $1 \mathrm{~b}$, the salesman would record his effort in his log book. The recording serves two purpose, oneno other sales person should contact them; two- tells the management about the activities of the sales staff. In case of $1 \mathrm{c}$, the salesman would like to record the call and a reminder to himself to contact again. A mechanism is required to remind the sales person to contact the party again. In case of $1 \mathrm{~d}$, he would like to record the details of the potential buyer along with requirements and move on to step number two.

2) All five components- items, quantity, price, delivery date- of the order, payment terms need to be dealt with.

3) The sales person after obtaining all required information, records them, creates a quote and (e) mails to the potential buyer. At present, Retails has paper files for each customer containing all communications.

4) The sales person is expected to make follow up calls to the potential customer and convert him into a customer. When the sales person contacts a potential customer again, any of the 4 key components of the order may get modified including items, price, quantity or delivery date. The sales man may have to do another iteration of steps 3 and 4 before actually receiving a order.

5) The material is shipped directly to the customer through a shipping agency. The shipping agency is also contacted and space on the shipping vessel is reserved by the salesman. The terms and conditions are also negotiated by the salesman.

6) All material is insured before transporting.

7) As soon as a potential order is in view, the purchase team has to become active. The interaction of the purchase team with with potential vendors is similar to the interaction of sales team with potential customers. We would not detail the purchase process further.

When we started talking to the CMD of Retails, he voiced many of his concerns and his reasons for wanting to deploy an ERP system. We mention his concerns next.

- Prices and their validity: Since the management team consists of only three people and they are multi-tasking, it is not unusual for them to forget to update the price list.

- Reduce Errors: There are multiple parameters associated with a product that RetailS deals in. A mistake or omission of one of the parameters may result in delay, cancellation or rejection of the entire order.

- Follow up: Retails needs to frequently follow up with their customers, vendors and shipping agents. A customer is contacted multiple times during the process of a sale that also requires staff to contact the vendors multiple times as well. An issue that management faces here is that the remaining sales team may not know about the call and others may also call the same potential buyer resulting in possible annoyance.

- Trade Secret: Retails has to protect price information from their existing competition and from the potential competition that may even shoot up from within Retails. The information should be available in a very selective manner to the employees.

- Reports: The management wants the organisational reports in real time in desired format.

RetailS started looking for an integrated solution and referred to it as ERP. We describe their efforts in the next section. 




Fig. 1. Sales process of RETAILS in event-driven process chain (EPC) format

\section{ERP IMPLEMENTATION AT RETAILS}

A high level team consisting of CMD, one managing director and an external consultant was formed. The activities that were undertaken are as follows.

Budget and Time Line: The data collected from various sources indicates that an ERP implementation costs around 1\% of the turnover of the company. For RetailS, this figure turns out to be INR. 50,000,00. As mentioned earlier, Retails is a very efficient company and this figure is way too high for an ERP implementation. Also, Retails is happy with a proprietary software that they use for their financial accounting and didn't want to include financial accounting in the ERP system. They wanted to move in a phased manner.

Retails expected the entire project to take about 6 months including requirements gathering and documentation, customisation by the vendor of his product, deployment and testing and data migration.

Vendor Selection: The consultant started looking for a vendor and an ERP solution. After spending about a month using all possible channels, two companies were considered, both were located in NCR region. Retails team decided to work with- let us call this company- $\mathrm{KN}$ and its CMD- $\mathrm{Mr}$. Tiwari (not his real name). His team members were just about average or below average. Mr. Tiwari showed his product that they delivered to another client. His claim was that he can quickly adapt the existing system to suit requirements of Retails. After 2 meetings, the terms and conditions of the contract were finalised and a time line for various phases that were in accordance to the schedule Retails had in mind. Everything got formalised and a contract between RetailS and $\mathrm{KN}$ was signed. The signing amount was paid to $\mathrm{KN}$ right away. The team consisted of the following:

- CMD, Retails: Champion and Business Process Owner

- Consultant: Interface between KN and RetailS

- Mr. Tiwari: Champion from KN

- Mr. Abhishek + 2 others: Project Manager + Developers + Tester

The work started by KN's team collecting requirements. During the meetings, the team seem to be taking notes but eventually it was discovered that the information didn't get collated properly. After couple of meetings, it became clear that the team is not equipped with the skill set required. After a period of almost 10 months and enormous amount of effort, the team had made no progress. The product showed initially didn't fit the requirements at all. During these 10 months, availability of KN's team and CMD, Retails were not as much as was required by the project. The consultant over-trusted KN and didn't carefully match the initial product that $\mathrm{KN}$ claimed to almost for RetailS. The consultant also didn't visit the company's office and no cross-check with KN's clients was done. After 10 months, the consulted briefed CMD, RetailS who then called Mr. Tiwari and his team for a discussion. After the discussion, Mr. Tiwari brought in another person, names Nimesh (not his real name) into the project and removed everyone else from the project. Nimesh quickly picked up the threads and started developing a product from the scratch.

CMD, Retails got busy with another business line that he was exploring. The work on the project completely stopped as he was just not available and he didn't depute anyone else 
on the project. There was a total gap for almost 6 months. In the mean time, the consultant moved from Delhi and got busy. After spending almost 15 months on the project, nothing got deployed. After the consultant settled down, Nimesh was contacted to continue the project. By now, Nimesh had moved on and he was no more interested in the project.

\section{Evaluation of the Project}

The ERP solution for RetailS never got deployed. The evaluation is done with the objective of learning from the mistakes and be able to enhance the chances of success next time around. The Table II. Lists identified factors critical to an ERP implementation success spread over all phases of the project including go-live and maintenance. The factors that apply to usage can be left out as RetailS never got to that phases. The factors- Education and Training, Data Management, Change Management and User Involvement are not relevant. The Environment and Organization Characteristics were supportive of the project. The remaining 8 factors were out of control and the deciding factors as we discuss next.

\section{A. ERP Project Management and Project Monitoring}

Project management includes among many other things a focus of project progress and constant tracking of schedules and budgets against targets [8]. In case of Retails, the project schedule kept slipping and the team from Retails was not able to control or bring the project back on schedule. The consultant was also not able to pick early signs of the problems as there was no formal monitoring of the project.

\section{B. Top Management Support}

The support from the management is required at multiple levels. The project must be aligned with the business strategy of the organisation. A change in the mindset is required that involves lot of learning by the management as well [9], [18]-[19]. In case of Retails, the management was reluctant to learn the language of ERP. CMD didn't want to validate the processes that were documented. The management wanted the vendor's team and the consultant to listen to them. In case of SMEs, key decisions are made by top management. For an ERP project, prompt decisions are required [20]. But due to multitasking by the management, their availability was also a major issue.

\section{Competence of the Project Team}

The vendor's team must be knowledgeable and cooperative [9]. This requirement is more pronounced in case of SMEs [20]-[21]. The men power that is available to SMEs to handle their IT is often inadequately trained and their knowledge is very superficial. In case of $\mathrm{KN}$, the vendor's team was not knowledgeable and the team members kept changing. There availability was also an issue. Subsequently, the cooperation between RetailS and the vendor decreased below acceptable limits.

\section{ERP System, Proper Package Selection and Software Development}

An ERP system is considered proper if it fits organisational data and processes requiring very little or no customisation [22]. Wrong package selection has been identified as a high risk is case of SMEs [21]. As explained earlier, in case of Retails, the vendor claimed a close fit of his ERP system with RetailS. Neither the consultant nor the Retails team went into the details to verify vendors claim. The ERP solution was just not appropriate and required major changes. A study in China has established that a SME may be able to find about $60 \%$ of fit and not more than that. What Retails experienced is not surprising. The consultant not being aware of the misfit is the surprising part.

\section{E. Implementation Strategy}

The use of consultant is part of the implementation strategy [4]. Consultant's role in an ERP project in a small organisation is very important due to insufficient internal expertise [23]. The consultant is required to have technical expertise as well as knowledge of the business. The consultant plays an important role in ERP package selection, implementation partner selection and managing the project. In [24], a scenario has been identified where small enterprises go for supplier/consultant driven ERP implementation. The management treats ERP implementation as an IT exercise and this has been cited as a reason for failure. In case of RetailS, IT department and expertise did not exist and the organisation had no choice but opt for supplier/consultant driven implementation. The responsibility of entire project was on the consultant. The consultant had the technical knowledge but lacked experience in handling ERP projects. The consultant was not able to control the project as expected. The slippage in the schedule, misfit with the package selected and too much customisation were the problems that the consultant failed to see in time to be able to bring back the project on track.

\section{CONCLUSION}

A small organisation does not have resources to adequately address all the CSFs [25]. A methodology for implementing ERP for SMEs has been developed [12], [26]-[27]. RetailS could have followed a similar methodology to enhance chances of success of its ERP project. A very sketchy account of the issues for ERP in developing countries include low penetration of IT, culture of treating computers as pervasive way of doing business, and perception that ERP is only for large organisations [28]. The impact of these issues can be seen on the organisations that implement ERP system (clients) and the ones that provide software and implementation services (vendor and consultants) [29].

The CSFs [23] have been shown to interact [17], [30] each other. But project Management, Project Team Competence and Top Management Support have been identified as the root causes of the failure. These conclusions are based on a case study. Retails case also supports these conclusions. Project management was very poor in case of Retails that negatively influenced package selection that in turn adversely impacted all other CSFs. More work is required to establish relationships between various CSFs and we leave that to be done in future.

\section{ACKNOWLEDGEMENT}

The author would like to thank Reatils for giving the opportunity to investigate their ERP project. 


\section{REFERENCES}

[1] R. Gioia. (2001). Project failure: Survey. [Online]. Available: http://www.systemsstudynotes.com/2010/04/project-failure-robbins-g ioia-survey.html, as seen on 26-Nov-2011.

[2] M. Al-Mashari, A. Al-Mudimigh, and M. Zairiet, "Enterprise resource planning: a taxonomy of critical factors," European Journal of Operational Research, vol. 146, pp. 352-64, 2003.

[3] A. Amid, M. Moalagh, and A. Z. Ravasan, "Identification and classification of ERP critical failure factors in Iranian industries," Information Systems, vol. 37, pp. 227-237, 2012.

[4] L. Shaul and D. Doron Tauber, "CSFs along ERP life-cycle in SMEs: a field study," Industrial Management \& Data System, vol. 112, no. 3, pp. 360-384, 2012.

[5] S. Bueno and J. L. Salmeron, "TAM-based success modeling in ERP," Interacting with Computers, vol. 20, pp. 515-23, 2008.

[6] C. Annamalai and T. T. Ramayah, "Does an implementation stage act as a moderator in Enterprise Resource Planning (ERP) Projects IN India? An Empirical Study," Journal of Research in Banking and Finance, vol. 2, no. 2, 2012.

[7] L. Ganesh and A. Mehta, "Critical Success Factors for Successful Enterprise Resource Planning Implementation at Indian SMEs," International Journal of Business, Management and Social Sciences, vol. 1, no. 1, pp. 65-78, 2010.

[8] P. Upadhyay and P. K. Dan, "An explorative study to identify the Critical Success Factors for ERP implementation in Indian small and medium scale enterprises," in Proc. International Conference on Information Technology, 2008, pp. 295-299.

[9] P. Upadhyay, R. Basu, R. Adhikary, and P. K. Dan, "A Comparative Study of Issues Affecting ERP Implementation in Large Scale and Small Medium Scale Enterprises in India: A Pareto Approach," International Journal of Computer Applications, vol. 8, no. 3, pp. 23-28, 2010.

[10] P. Upadhyay, S. Jahanyan, and P. K. Dan, "Factors influencing ERP implementation in Indian manufacturing organisations- A study of micro, small and medium-scale enterprises," Journal of Enterprise Information Management, vol. 24, no. 2, pp. 130-145, 2011.

[11] Y. Li, "ERP adoption in Chinese small enterprise: an exploratory case study," Journal of Manufacturing Technology Management, vol. 22, no. 4, pp. 489-505, 2011

[12] Y. Xia, P. Peter Lok, and S. Yange, "ERP Implementation of SME in China," ICSSSM '09, 2009, pp. 135-140.

[13] F. A. Goni, A. G. Chofreh, and S. Sahran, "Critical Success Factors for Enterprise Resource Planning System Implementation: A Case Study in Malaysian SME," in Proceeding of the International Conference on Advanced Science, Engineering and Information Technology, pp. 200-205, 2011.

[14] S. M. Jafari et al., "ERP systems implementation in Malaysia: the importance of critical success factors," International Journal of Engineering and Technology, vol. 3, no. 1, pp. 125-131, 2006.

[15] A. Noudoostbeni et al., "An Effective End-User Knowledge Concern Training Method in Enterprise Resource Planning (ERP) Based on Critical Factors (CFs) in Malaysian SMEs," International Journal of Business and Management, vol. 5, no. 7, pp. 63-76, 2010.

[16] S. E. Sawah, A. A. E. F. Tharwat, and M. H. Rasmy, "A quantitative model to predict the Egyptian ERP implementation success index," Business Process Management Journal, vol. 14, no. 3, pp. 288-306, 2008.

[17] K. Salimifard, M. Ebrahimi and M. A. Abbaszadeh, "Investigating Critical Success Factors in ERP Implementation Projects," IEEE
International Conference on Advanced Management Science, 2010, pp. $82-86$.

[18] P. Bingi, M. K. Sharma, and J. K. Golda, "Critical issues affecting an ERP implementation," Information Systems Management (Summer), pp. 7-14, 1999.

[19] S. L. Jarvenpaa and B. Ives, "Executive involvement and participation in the management of information technology," MIS Quarterly, vol. 15, no. 2, pp. 205-27, 1991.

[20] Y. Zhang, "An Analysis on the ERP Application Status of the Small and Medium Manufacturing Enterprises," Second International Conference on Communication Systems, Networks and Applications, 2010, pp. 165-168.

[21] P. Iskanius, "The ERP Project Risk Assessment: A case study," in Proc. the World Congress on Engineering, 2009, vol. 1, pp. 8-12.

[22] I. J. Chen, "Planning for ERP systems: Analysis and future trend," Business Process Management Journal, vol. 7, no. 5, pp. 374-86, 2001.

[23] T. M. Somers and K. G. Nelson, "A taxonomy of players and activities across the ERP project life cycle," Information and Management, vol. 41, pp. 257-278, 2004

[24] A. Marsh, "The Implementation of Enterprise Resource Planning Systems in Small-Medium Manufacturing Enterprises in South-East Queensland: A Case Study Approach," ICMIT, 2000, pp. 592-597.

[25] A. Y. T. Sun, et al., "Achievement assessment for enterprise resource planning (ERP) system implementations based on critical success factors (CSFs)," International Journal of Production Economics, vol. 98, pp. 189-203, 2005.

[26] K. Fu, "Development of a Generic Procedure Model for the Enterprise Resource Planning Implementation in Small and Medium Enterprises," in Proc. SICE Annual Conference, 2010, pp. 3523-3528.

[27] M. Y. Zain, "Minimizing The Problems Of Enterprise Resource Planning (ERP) Implementation For Small To Medium Cigarette Company Through Framework For Applications Of Systems Thinking (FAST)," Media Informatika, vol. 6, no. 1, pp.57-69, 2008.

[28] Z. Huang and P. Palvia, "ERP implementation issues in advanced and developing countries," Business Process Management Journal, vol. 7, no. 3, pp. 276-284, 2001

[29] B. Snider, G. J. C. D. Silveira, and J. Balakrishnan, "ERP implementation at SMEs: analysis of five Canadian cases," International Journal of Operations $\mid \&$ Production Management, vol. 29, no. 1, pp. 4-29, 2009.

[30] H. Akkermans and K. V. Helden, "Vicious and virtuous cycles in erp implementation: a case study of interrelations between critical success factors," European Journal of Information Systems, vol. 11, pp. 35-46, 2002.

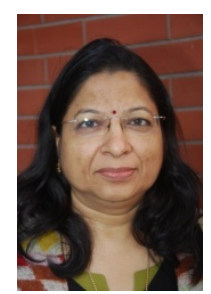

Veena Bansal received her M.S. from Univ. Of Connecticut, USA and PhD from IIT Kanpur in 1999. She is on the faculty of Industrial and Management Engineering, Indian Institute of Technology Kanpur since then. She has widely travelled across the globe to attend school, to teach and to present her research work. She has conducted multiple SAP workshops for the faculty and industry. Her published work on Devanagari Optical Character Recognition has become key reference for researchers working on Indian scripts. 